\title{
Looking back, moving forward: the place of evaluation at the Tangentyere Council Research Hub
}

Matthew Campbell
Tangentyere Research Hub
matthew.campbell@tangentyere.org.au
Denise Foster
Tangentyere Research Hub
denise.foster@tangentyere.org.au
Vanessa Davis
Tangentyere Research Hub
vanessa.davis@tangentyere.org.au

Note: This paper, at the request of the authors, did not go through an academic peer review process. However, the authors are happy to present their views where others can see them, including other Indigenous researchers and evaluators.

Keywords: Tangentyere Research Hub, role of Elders in Aboriginal evaluation, Alice Springs Town Camps, Aboriginal evaluation, Aboriginal control of research, Aboriginal control of evaluation, Tangentyere Council.

\begin{abstract}
Tangentyere Council is a very important organisation for Aboriginal people living in Alice Springs. The Tangentyere Council Research Hub has been going now for more than ten years, based on two core philosophies: 'researching ourselves back to life' and 'no survey without service'. We rely on Aboriginal research practices and Aboriginal understandings of evaluation as part of this practice. In this paper we will talk about our organisation and its history as well as the research work we do. What we hope to do is to set out what evaluation means for us in terms of the work that we do, and how being aware of this helps us to keep our knowledge and organisation strong. We also hope that it might help others working with Aboriginal people to think differently about evaluation and maybe even approach it differently in the future.
\end{abstract}




\section{Tangentyere Council}

Tangentyere Council has a long history in Alice Springs. It began operating in the early 1970s and was first incorporated in 1979. It is the major service delivery agency for 17 of the 18 Housing Associations known as 'Town Camps' in Alice Springs (Tangentyere Council, 2014).

Tangentyere Council was established by Aboriginal people from what were called the 'fringe camps', areas of Crown land around Alice Springs where Aboriginal people lived but to which they had no formal title. These fringe camps were as old as Alice Springs itself. Tangentyere was formed so that we could get legal tenure for the land we were living on in order to obtain essential services and housing. Since its incorporation in 1979 , it has grown into an organisation with a workforce of $243,61 \%$ of whom are Aboriginal.

It is difficult to estimate the population of the Town Camps; the estimated population in Tangentyere's 2005 Mobility Report was between 1,765 and 2,065 people (Foster, Mitchell, Ulrik \& Williams, 2005). Given the expansion of Town Camp housing infrastructure, particularly since 85 new houses were built under the Strategic Indigenous Housing and Infrastructure Program (SIHIP), it is hard not to imagine there has been an increase. The service population is likely to be larger again, with people from remote communities all over central Australia coming into Alice Springs, which is the only large service centre in the region.

Each Town Camp comprises an Indigenous community, based on language and kinship groups, which often had its origins prior to the formation of Tangentyere. The majority of Town Camps have Arrernte residents, who are the Traditional Owners of Alice Springs and its immediate surrounds. Many Town Camps also have residents who belong to language groups whose traditional lands are found across central Australia, but who have moved to Alice Springs over a period of time for various reasons. Town Camp residents often have strong links with remote communities and there is substantial mobility between bush and town.

While Town Camps are located in Alice Springs, residents are often culturally and linguistically isolated from the services available. Provision of services by Tangentyere Council, often in partnership with government and other non-government organisations, means that Town Camp residents have access to services which they would otherwise miss out on.

Tangentyere Council was set up to gain access to land and to provide housing and other vital infrastructure, and since its inception the management of this housing was a core function. However since the takeover of Aboriginal housing in 2007 by the Commonwealth government as part of the Northern Territory Intervention (Commonwealth Ombudsman, 2012), Tangentyere Council no longer has any role in the day to day management of housing. Today, Tangentyere Council runs a range of family and youth services, a night patrol, day patrol and youth patrol, a research hub, an art centre, an aged and community care program, a community banking facility and five not for profit enterprises. 
This background has been provided to show that Town Camp residents are, and have always been, determined to be in control of their own affairs, assert their rights to a maintain their distinctive Aboriginal identities, and to build and maintain institutions to help them to do this. It is within this milieu that the Tangentyere Council Research Hub came to life in the early years of the 21 st century, with its initial motto of 'researching ourselves back to life'. As a research space dedicated to making a difference in the lives of Town Camp residents, evaluation has come to take on critical importance.

In the following section we identify a number of things about our research and evaluation that we think are important. These points are summarised from internal discussions we held to reflect on the place of evaluation in our work.

\section{The importance of control over research}

When we set up the Research Hub, we took control of our own research. One of the things we saw so much of was other people controlling research in our communities. When they control the research then they don't have to do things the right way. We already knew, from our own way of understanding research, that doing things the right way is very important. It is wrong for people from other places to come in, ask questions, learn things and then go away and get qualifications from the knowledge that really belongs to Aboriginal people. We have talked to many people who are unhappy about this, especially when these people didn't come back and report on what work they'd done and what they'd found. For us, this is a breach of trust in the knowledge making process. Taking control of research means that we decide what is important, we decide what questions need to be asked, we decide the process. When we do this, we know how to do it in the right way, and this means that not only do we learn new things, but we strengthen ourselves as professional researchers. Also, when we are in control we strengthen our own community because using our own knowledge is strength.

\section{Research is not about finding things out, it's about making a difference}

Our original motto for the Research Hub was 'researching ourselves back to life'- our work is not just about 'finding things out' but about 'making a difference'. For us, doing research is only worthwhile if it makes a difference to the people in the camps. Making a difference means making our people, families and camps stronger.

\section{What we mean by evaluation}

Sometimes Government wants to do evaluations to see how things are working. Often they send people in to do research or evaluation and then these people go away and make decisions. This is not our way. What we mean by evaluation is the way we find better ways to make a difference in our lives and in our community. We are still learning 
about the different ways 'making a difference' can be understood (and that is part of our ongoing evaluation). One of our key values is doing work that makes a difference. It is our processes of evaluation that have helped us to learn this, and to keep trying to make it part of our work. One of the keys for this is how we work with the Elders. They are an important part of teaching us our evaluation.

We have made two drawings for this article. Figure 1 shows the right way to do evaluation, making connections before starting the research, and getting direction from the Elders. Figure 2 shows the way that an evaluation can be done the wrong way, with external researchers/evaluators just trying to go straight to Town Camp residents.

\section{The role of Elders in knowledge making}

The most important thing to understand is that the Elders are the most important people in our community. Showing respect for them is how we keep our families and communities strong, and we rely on their experience and wisdom to guide us, especially when we are trying new things or are unsure about what we should do. Part of our job in research is to go to the Elders for guidance. When we do this we show them that their knowledge and experience is important, and at the same time they give us their blessing to do the work we do. This makes sure that other people also see that we are doing our research the 'right way', and because we are doing it the right way they can support us and get involved too. One of the important things we have learned from the Elders is that we need to be connecting up our work with the past. 
Figure 1: Doing evaluation the right way

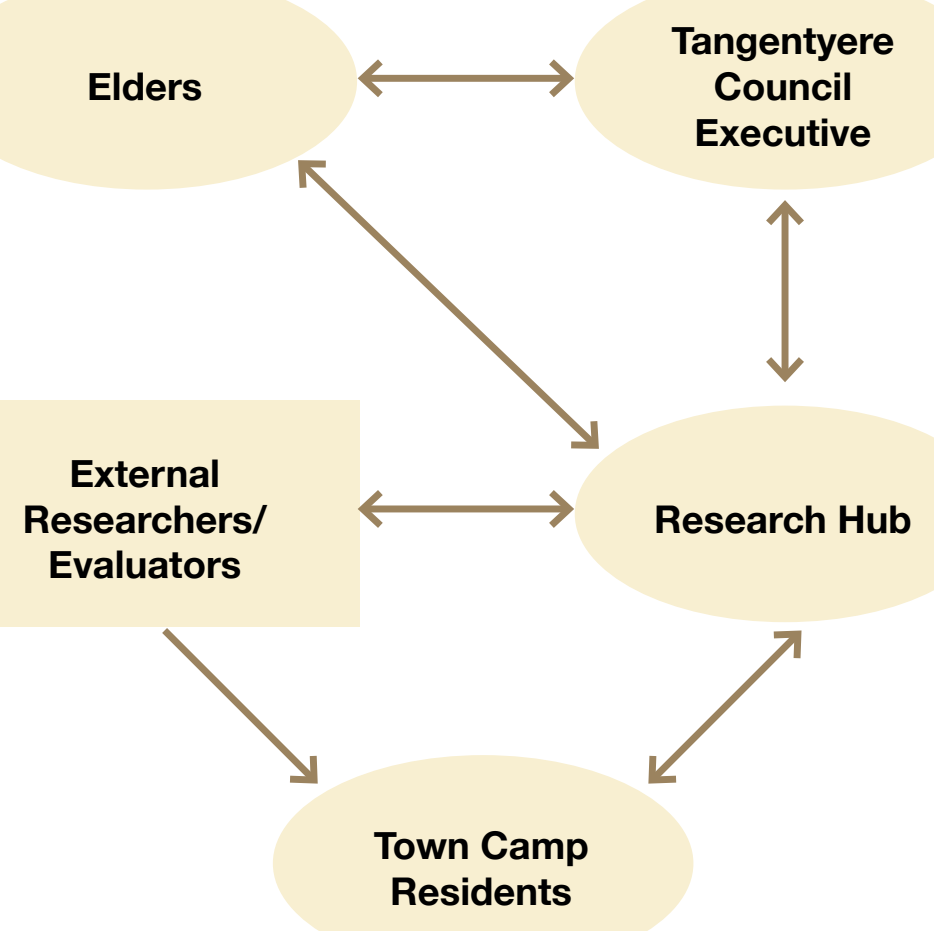

1. External evaluator wishes to evaluate a program for Town Camp residents

2. External evaluator contacts Tangentyere Research Hub

3. Research Hub seeks approval from Tangentyere Executive to proceed

\section{Decision making point}

4. External evaluator works with the Research Hub to devise questions and methodology

\section{Decision making point}

5. Researchers liaise with the right elders to discuss the project

6. Researchers (with or without external evaluators) do on ground work with Town Camp residents

7. Researchers and external evaluators analyse data and come up with tentative findings

8. Tentative findings are shared with elders and Executive - changes made where necessary

Decision making point

9. Findings are reported to the elders, the Executive and the Town Camp residents

10. Findings are reported externally 
Figure 2: Doing evaluation the wrong way

Elders

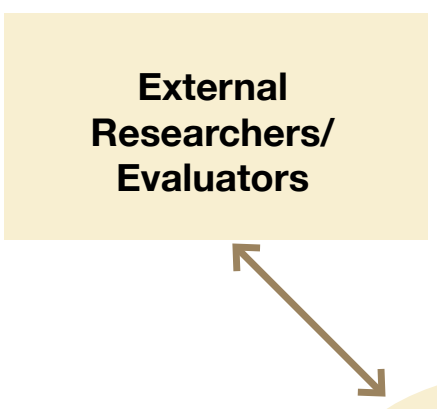

\section{Tangentyere \\ Council \\ Executive}

\section{Town Camp \\ Residents}

1. External evaluator wishes to evaluate a program

\section{Research Hub}

2. External evaluator devises questions

Decision making point

3. External evaluator approaches people in town camps

4. External evaluator analyse data and come up with findings

Decision making point

5. External evaluator presents findings to external audience (and perhaps to residents)

\section{Connecting up with the past}

Evaluation for us is less about 'looking back to learn for next time'; instead, it is focused on 'making sure we are connecting up with the past'. When we say 'connecting up with the past' it might make it sound as if we are only interested in what went before - something like doing history work, but this is not what we mean. What we mean is, whatever we do, we have an important job to show how what we are doing builds on the work that was done before, not just by us as researchers, but everyone in the Town Camps. People in the Town Camps want to see how the work we do builds us up and keeps us strong as Aboriginal people, and so we need to be able to show people this. 
People might worry that this might mean that we do not consider how evaluation assists us to do things differently in the future. This is not the case; we are always looking both forwards and backwards. We need to look forward, but we also have to think about what we are doing now. What we do creates what comes next. If we did not think about this, we would just keep on making mistakes. However, because our job is also to build up our communities, we need to build on what was done in the past. The old people fought those fights so we can be here doing what we are doing today. We respect them by connecting our work with theirs. We are only standing here today because of those who came before us. Without them, we are nothing. Evaluation helps us to remember we are continually building the foundation upon which those who come after us will stand.

\section{How do we do this connecting work?}

It's a bit hard to talk easily about how we do this connecting work as it is really just a part of our day to day lives. But it is important that we try to show how we do it, because we think it is something that other researchers should be doing too - other researchers can help us to do this work, or they can be helping others in other places. Most of our evaluation takes place as we do our work. We are going backwards and forwards to our Elders all the time, talking about the projects we do; we are learning from them about how to do research properly. They are always talking about how important it is to talk to the right people, and they teach us how to build or keep connections between people and families. This is important in Aboriginal knowledge making. They also tell us if our research is valued, and what we might think about doing next time. Most of our evaluation occurs in our day to day conversations. Some people might think that proper evaluation should be more formal; however our authority to do this work comes from these conversations. These Elders are helping us to do the important work of connecting what we do with what we've done before, and with what others have done before. As we move on to become Elders in our community, we will take up this role.

\section{Evaluation helping us to focus on what is important}

Evaluation is also part of helping us to keep our minds on our relationships with the Town Camps. We are not really separate from the Town Camps and we rely on them, and they rely on us. Evaluation has helped us to be very clear about what is important to us and the people we work with, and the main thing is good trusting, respectful relationships. If we don't have this then we can't do our work. And the thing for us is, if we do the wrong thing that doesn't just affect 'this' project; it affects every project we might want to do in the future. It's because of this that we are very careful about how we do things, the questions we ask, and how we give information back. We are not like outside researchers, who can come in, do the wrong thing and go away. We will be living here forever, so we cannot do anything that makes a problem. 


\section{Evaluation to keep our organisation strong}

Another important part of evaluation is thinking about how does it help to make our organisation strong? Tangentyere is interesting because it is made up of all the Housing Associations that set up each Town Camp in the first place. This means Tangentyere can do things that the each little Town Camp cannot. It can be really hard when people from different Town Camps have different ideas and opinions. The Research Hub is one place where we talk to people from all the camps, and can put their stories together so we can tell others about them. Part of what we do is bring the different Town Camps together, showing that we can be different, but at the same time there are things that keep us connected. We know we are doing our work well when it plays a part in Tangentyere talking up strong in discussions about issues in Alice Springs. At the moment, the value of our work is being recognised through projects looking at alcohol management and chronic disease management. In both of these projects, our work contributes to Tangentyere being able to play a leading role in getting the stories of the people of the Town Camps heard.

\section{Final reflections}

Evaluation is something that we do all the time in our work; we can't separate it from our research work. Aboveall, we value three main things: our relationships with ourElders, and how ourwork can strengthenourold peopleand theirpositionas theknowledgeauthorities in our communities; our relationships with people in the Town Camps; and making sure we connect up our work with the past.

The Elders are the people who help us to understand our place in the world, and guide us to do work that makes a difference for the people in our communities - the Town Camps of Alice Springs. At the moment, most of our evaluation takes place behind the scenes, in all the conversations we have around our work. As we go on, we want to get better at capturing this process, but as we do so, we will never lose sight of the fact that we are here today, doing our work in our own way. For us, this is evidence that our work is valuable, not only to us, but to our families and communities as well.

For others, we want you to know that you can help us to do this work. You can do this by listening to us about how research should be done, and giving us the time to talk properly and respectfully with our Elders. If you can do this, then it means that research is being done properly in our way. If you can do this, then you will help us as individuals and you will help our communities; but you might also find that you learn something new about how our knowledge is made too.

For us, the past is so important. Whatever is happening now is happening because of what happened before. If we forget this we are in danger of not learning, but also in danger of breaking our connections. This connection with the past is an important part of our strength and who we are as Aboriginal people. As Aboriginal people we have had to fight many fights to have our rights recognised. Those old people who fought those fights did them for us, and for the people who come after us. If we forget them, we 
undermine our own strength. We also know that we are not in this alone. We recognise the people who fought, and who continue to fight alongside us. Understanding the past and learning from it, connecting it with what we do today, is something we need to do in every project. For many of us, we are still fighting to make our lives better.

\section{References}

Commonwealth Ombudsman. (2012). Remote housing reforms in the Northern Territory. Canberra, Australia. Retrieved from Commonwealth Ombudsman's website: http://www.tangentyere.org.au/publications/research_reports/DKCRCReport-9-Population-and-Mobility-in-the-town-camps-of-Alice-Springs.pdf

Foster, D., Mitchell, J., Ulrik, J., \& Williams, R. (2005). Population and Mobility in the Town Camps of Alice Springs, A report prepared by Tangentyere Council Research Unit, Desert Knowledge Cooperative Research Centre, Alice Springs. Retrieved from: http://www.tangentyere.org.au/publications/research_reports/ DKCRC-Report-9-Population-and-Mobility-in-the-town-camps-of-AliceSprings.pdf

About Us. (n.d.) Tangentyere Council. Retrieved from http://www.tangentyere.org.au/ 


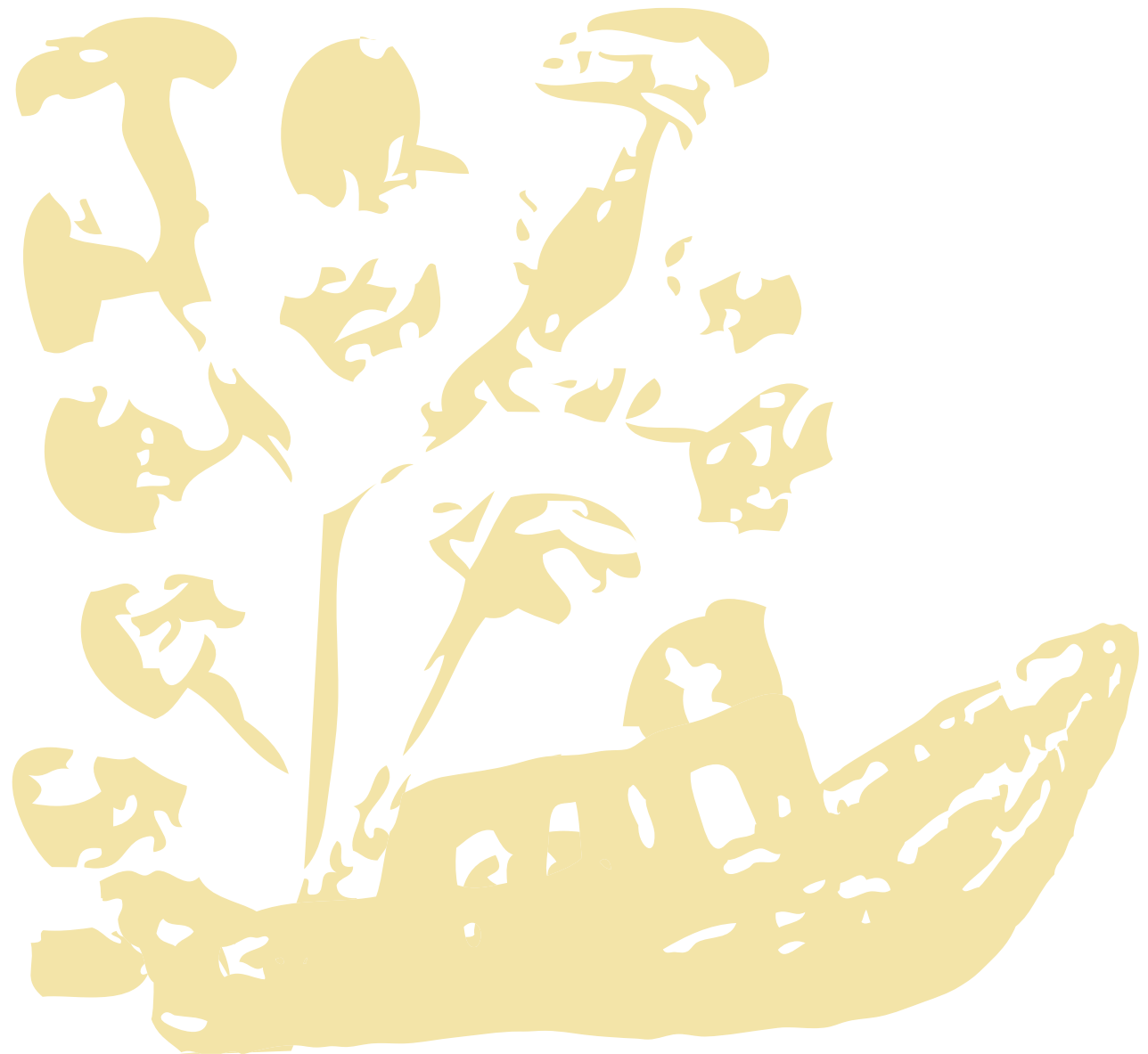

